\title{
The validity of commonly used haematological indices in the detection of iron deficiency in pregnancy
}

\author{
I. M. R. Goonewardene' , R. J. Fernando ${ }^{1}$, C. Liyanage ${ }^{2}$ and K. G. Somasiri ${ }^{3}$ \\ The Ceylon Journal of Medical Science 2001; 44: 29-34
}

\section{Summary}

Rationale: The haemoglobin concentration $(\mathrm{Hb})$ has limitations in the diagnosis of iron deficiency in pregnancy.

Objective: The objective of this study was to assess the validity of the accepted cut off points of the other commonly measured haematological indices in either detecting or excluding iron deficiency as determined by the serum ferritin (SF) assay.

Design: A cross sectional study was carried out on two groups of women in the second and third trimesters of pregnancy.

Setting: University Antenatal Clinic, Faculty of Medicine and Kyoto Medical Centre Galle.

Method: The $\mathrm{Hb}$, haematocrit (Hct), mean corpuscular volume (MCV), mean corpuscular haemoglobin (MCH), mean corpuscular haemoglobin concentration $(\mathrm{MCHC})$ and red blood cell count (RBCC) were estimated by an automated haematology analyser and compared with the SF levels measured by immunoradiometric assay, in 156 women in the second trimester $\left(\mathrm{T}_{2}\right)$ and 47 women in the third trimester $\left(\mathrm{T}_{3}\right)$ of pregnancy. The sensitivity, specificity, positive predictive value, negative predictive value, accuracy and the Kappa statistic were calculated for the accepted cut off points for diagnosis of anaemia, for each haematological index, using a $\mathrm{SF}<12 \mu \mathrm{g} / \mathrm{L}$ as the diagnostic criterion for iron deficiency.

Results: The Hct, MCV and MCHC had a high specificity (96-100\%) but a very low sensitivity (10-38\%). Only the $\mathrm{MCH}$ had a high sensitivity $\left(92 \%\right.$ in $\mathrm{T}_{2}, 86 \%$ in $\mathrm{T}_{3}$ ) but it had a low specificity $(21-24 \%)$. The MCHC had the best accuracy $(71 \%$ in T3) but its accuracy in $\mathrm{T}_{2}$ was only $64 \%$. Only the $\mathrm{MCHC}$ in $\mathrm{T}_{3}$ showed some agreement with $\mathrm{SF}$ (Kappa 0.41, $\mathrm{p}=0.00$ ).

Conclusion: A single haematological index per $s e$ has a poor ability of detecting or excluding iron deficiency in pregnancy. Although the best index is the MCHC, its accuracy is only $64 \%$ in the second trimester. Therefore several indices should be evaluated before deciding on a diagnosis of iron deficiency and subsequent supplementation or therapy during pregnancy.

Key words: haematological indices, iron deficiency, pregnancy, validity.

\section{Introduction}

The haemoglobin concentration $(\mathrm{Hb})$ is poorly correlated to the iron stores of a subject as the $\mathrm{Hb}$ is maintained within normal limits until the iron stores are depleted, and therefore is of limited value in the detection of iron deficiency $(1,2,3,4)$. Iron stores are usually assessed by serum ferritin (SF) assays $(1,2,3)$. The $\mathrm{Hb}$ is also reduced by folate and vitamin $B_{12}$ deficiencies. The only known cause for a low SF level is iron deficiency $(1,2,3)$. A low $\mathrm{Hb}$ associated with low SF levels is due to iron deficiency anaemia. The objective of this study was to assess the validity of the accepted cut off points of the other commonly measured haematological indices in either detecting or excluding iron deficiency, as determined by the SF assay.

\section{Methods}

A cross sectional study was carried out on two groups of women in the second and third trimesters of pregnancy. The criteria for selection

1. Departments of Obstetrics and Gynaecology,

2,3. Community Medicine and Physiology, University of Ruhuna, Galle, Sri Lanka. 
of subjects was that they should have a period of gestation (POG) either between 14-24 weeks (group A) or between 28-40 weeks (group B).

From the pregnant women presenting themselves at the university antenatal clinic in Galle, 203 consecutive women who fulfilled the selection criteria were recruited for the study. Of these women, 156 women (group A) were in the second trimester $\left(T_{2}\right.$, POG 14 - 24 weeks) and 47 women (group $B$ ) were in the third trimester $\left(T_{3}\right.$, POG 28 - 40 weeks). Assuming the prevalence of iron deficiency to be approximately $70 \%(4), 323$ subjects would be required to tolerate a maximum sampling error of $5 \%$ (5). However the actual sample had to be curtailed to 203 subjects on account of the limited availability of the SF assay. Therefore, the possible sampling error in this study is approximately $6.5 \%$.

The potential benefits of the study were explained and informed consent was obtained from all the subjects. Ethical approval for the study was obtained from the Faculty of Medicine, Galle.

During venepuncture for the other routine antenatal investigations an additional $3 \mathrm{ml}$ and 4 $\mathrm{ml}$ of mixed venous blood was taken and divided into $1 \mathrm{ml}$ aliquots in group A and group B respectively. One aliquot in each group was collected into a bottle containing $0.1 \mathrm{ml}$ of ethylene diamine tetra acetic acid and transported to the Kyoto Medical Centre in Galle, where the $\mathrm{Hb}$, haematocrit (Hct), mean corpusular voulme (MCV), mean corpusular haemoglobin concentration (MCHC) and red blood cell count ( $\mathrm{RBCC}$ ) were estimated using an automated haematology analyser (Sysmex K-1000, TOA Medical Electronics Co. Ltd. Japan).

Another aliquot of blood from each group was transported to the Faculty of Medicine, Galle where SF was estimated by immunoradiometric assay technique using IRMA Ferritin kits (Diagnostic Products Corporation, Los Angeles) which detects SF levels of $0.1 \mu \mathrm{g} / \mathrm{L}$ or more. The balance blood was used for another part of this study programme.

Anaemia was defined as $\mathrm{Hb}<110 \mathrm{~g} / \mathrm{L}$ during pregnancy $(1-3,6-8)$. Iron deficiency was defined as $\mathrm{SF}<12 \mu \mathrm{g} / \mathrm{L}(1,2,3)$. A Hct $<32 \%, \mathrm{MCV}<80 \mathrm{fl}$, $\mathrm{MCH}<30 \mathrm{pg} / \mathrm{L}, \mathrm{MCHC}<30 \%$ and RBCC $<4.1$ million $/ \mathrm{mm}^{3}$ were considered as being low and indicative of iron deficiency $(1,2,3,6,9,10)$.

The sensitivity, specificity, positive predictive value, negative predictive value and accuracy were calculated for the accepted cut off points for each haematological index using a $\mathrm{SF}<12 \mu \mathrm{g} / \mathrm{L}$ as the diagnostic criterion for iron deficiency (11). The agreement between each haematological index and the SF assay in detecting or excluding iron deficiency was measured using the Kappa Statistic (12). Each haematological index was converted to a categorical variable using the accepted cut off point for this purpose. For the purpose of this study SF was considered as the 'gold standard' although it too has its limitations $(6,13-15)$.

\section{Results}

The distribution of the basic characteristics of the subjects are shown in Tables 1 and 2.

Table 1

The basic characteristics in Group $A$ $\left(n=156, T_{2}\right)$

\begin{tabular}{|l|c|c|c|}
\hline Characteristic & Mean & SD. & $95 \% \mathrm{CI}$ \\
\hline Age (yrs) & 26.3 & 6.1 & $14-43$ \\
\hline Parity & 1.9 & & \\
\hline POG. (Weeks) - T 2 & 19.4 & 2.9 & $14-24$ \\
\hline
\end{tabular}

Mean $=$ Arithmetic mean S.D $=$ Standard deviation $\mathrm{CI}=$ Confidence interval $\quad \mathrm{POG}=$ Period of gestation

Table 2

The basic characteristics in Group $B\left(n=47, T_{3}\right)$

\begin{tabular}{|l|r|l|l|}
\hline Characteristic & Mean & SD. & 95\%CI \\
\hline Age (yrs) & 26.3 & 5.6 & $15-38$ \\
\hline Parity & 2 & & \\
\hline POG. (Weeks) - $\mathrm{T}_{3}$ & 35 & 2.5 & $28-40$ \\
\hline
\end{tabular}

See Table 1 for meaning of abbreviations. 
Iron deficiency $(\mathrm{SF}<12 \mu \mathrm{g} / \mathrm{L})$ was found in $62(40 \%)$ of subjects in group $A\left(n=156, T_{2}\right)$ and $22(46 \%)$ in group $B\left(n=47, T_{3}\right)$.
The distribution of the haematological indices obtained by the autoanalyser and the SF values obtained by immunoradiometric assay are shown in Tables 3 and 4.

Table 3

Haematological indices and SF values in Group $A\left(n=156, T_{2}\right)$

\begin{tabular}{|c|c|c|c|c|c|}
\hline & & Mean & SD. & $95 \% \mathrm{CI}$ & $\mathrm{CV}$ \\
\hline $\mathrm{Hb}$ & $(\mathrm{g} / \mathrm{L})$ & 11.4 & 1.2 & $11.2-11.6$ & 0.11 \\
\hline Hct & $(\%)$ & 36.1 & 3 & $35.6-36.6$ & 0.08 \\
\hline $\mathrm{MCV}$ & (fl) & 89.5 & 5.3 & $88.7-90.3$ & 0.06 \\
\hline $\mathrm{MCH}$ & $(\mathrm{pg} / \mathrm{L})$ & 28.3 & 3.1 & $27.8-28.8$ & 0.11 \\
\hline $\mathrm{MCHC}$ & $(\%)$ & 31.7 & 0.2 & $31.3-32.1$ & 0.01 \\
\hline RBCC & (million $/ \mathrm{mm}^{3}$ ) & 4.2 & 1.7 & $3.9-4.4$ & 0.40 \\
\hline & $(\mu \mathrm{g} / \mathrm{L})$ & 19.7 & 16.5 & $17.1-22.3$ & 0.84 \\
\hline
\end{tabular}

$\mathrm{CV}=$ Coefficient of variation; See Table 1 and text for the meaning of other abbreviations.

Table 4

Haematological indices and SF values in Group $B\left(n=47, T_{3}\right)$

\begin{tabular}{|c|c|c|c|c|c|}
\hline & & Mean & SD. & $95 \% \mathrm{CI}$ & $\mathrm{CV}$ \\
\hline $\mathrm{Hb}$ & $(\mathrm{g} / \mathrm{L})$ & 12 & 1.4 & $11.6-12.4$ & 0.12 \\
\hline Hct & $(\%)$ & 39.9 & 7.2 & $37.7-42.0$ & 0.18 \\
\hline $\mathrm{MCV}$ & (fl) & 89.1 & 6.6 & $87.1-91.1$ & 0.07 \\
\hline $\mathrm{MCH}$ & $(\mathrm{pg} / \mathrm{L})$ & 32.6 & 3.7 & $22.6-42.6$ & 0.11 \\
\hline $\mathrm{MCHC}$ & $(\%)$ & 30.9 & 1.6 & $30.4-31.4$ & 0.05 \\
\hline $\mathrm{RBCC}$ & (million $/ \mathrm{mm}^{3}$ ) & 4.4 & 0.6 & $4.2-4.6$ & 0.14 \\
\hline SF & $(\mu \mathrm{g} / \mathrm{L})$ & 16.5 & 13.7 & $12.5-20.6$ & 0.83 \\
\hline
\end{tabular}

See Table 1 and text for the meaning of abbreviations. 
The overall accuracy of detecting or excluding iron deficiency was poor in all indices with $\mathrm{MCHC}$ in $\mathrm{T}_{3}$ having the highest accuracy $(71 \%)$. The accuracy of $\mathrm{Hb}$ in detecting or excluding iron deficiency was $65 \%$ in $\mathrm{T}_{2}$ and $67 \%$ in $\mathrm{T}_{3}$. The $\mathrm{MCH}$ was only index which had a good sensitivity $(92 \%$ in $\mathrm{T}_{2}$ and $86 \%$ in $\mathrm{T}_{3}$ ) but it had a poor specificity. Other than the $\mathrm{MCH}$ and $\mathrm{RBCC}$, all the other indices had good specificities. MCV had the best specificity $(98 \%)$ in $\mathrm{T}_{2}$ and $\mathrm{MCHC}$ had a $100 \%$ specificity in $\mathrm{T}_{3}$. Except for the $\mathrm{MCHC}$ which had a moderate agreement (Kappa 0.41, $\mathrm{p}=0.00$ ) none of the other indices had any agreement with the SF levels in the detection and exclusion of iron deficiency (Tables 5 and 6).

Table 5

The Kappa statistic and the validity of each haematological index in detecting or excluding iron deficiency in the subjects in group $A\left(n=156, T_{2}\right)$

\begin{tabular}{|ll|l|l|l|l|l|l|l|}
\hline & & Sen. & Spec. & PPV & NPV & Acc. & Kappa & p \\
\hline $\mathrm{Hb}$ & $<110 \mathrm{~g} / \mathrm{l}$ & 0.48 & 0.77 & 0.58 & 0.69 & 0.65 & 0.25 & 0.001 \\
\hline $\mathrm{Hct}$ & $<32 \%$ & 0.18 & 0.97 & 0.79 & 0.63 & 0.65 & 0.10 & 0.03 \\
\hline $\mathrm{MCV}$ & $<80 \mathrm{fl}$ & 0.10 & 0.98 & 0.75 & 0.62 & 0.62 & -0.02 & 0.99 \\
\hline $\mathrm{MCH}$ & $<30 \mathrm{pg} / 1$ & 0.92 & 0.21 & 0.44 & 0.80 & 0.50 & -0.07 & 0.99 \\
\hline $\mathrm{MCHC}$ & $<30 \%$ & 0.14 & 0.97 & 0.75 & 0.62 & 0.64 & -0.03 & 0.99 \\
\hline $\mathrm{RBCC}$ & $<4.1 \mathrm{million}$ \\
\hline
\end{tabular}

Sen.$=$ Sensitivity $\quad$ Spec.$=$ Specificity $\quad P P V=$ Positive predictive value $\mathrm{NPV}=$ Negative predictive value Acc. $=$ Accuracy

See text for the meaning of other abbreviations. 
Table 6

The Kappa statistic and the validity of each haematological index in detecting or excluding iron deficiency in the subjects in group $B\left(n=47, T_{3}\right)$

\begin{tabular}{|ll|c|c|c|c|l|l|l|}
\hline & & Sen. & Spec. & PPV & NPV & Acc. & Kappa & p \\
\hline $\mathrm{Hb}$ & $<110 \mathrm{~g} / 1$ & 0.38 & 0.92 & 0.80 & 0.64 & 0.67 & -0.12 & 0.49 \\
\hline $\mathrm{Hct}$ & $<32 \%$ & 0.10 & 0.96 & 0.67 & 0.56 & 0.57 & -0.01 & 0.58 \\
\hline $\mathrm{MCV}$ & $<80 \mathrm{fl}$ & 0.19 & 0.96 & 0.80 & 0.58 & 0.61 & 0.16 & 0.05 \\
\hline $\mathrm{MCH}$ & $<30 \mathrm{pg} / 1$ & 0.86 & 0.24 & 0.49 & 0.67 & 0.52 & 0.08 & 0.22 \\
\hline $\mathrm{MCHC}$ & $<30 \%$ & 0.38 & 1.0 & 1.0 & 0.66 & 0.71 & 0.41 & 0.00 \\
\hline $\mathrm{RBCC}$ & $<4.1 \mathrm{million}$ \\
\hline
\end{tabular}

See Table 5 for meaning of abbreviations.

\section{Discussion}

The level of SF has been recommended as a suitable index to detect iron deficiency $(1,2,3,6)$. However the SF is subject to biological day to day variations (13). It has also been shown that assessment of serum transferrin receptors, in addition of SF improves the detection of iron deficiency during pregnancy $(14,15)$. However, both SF and serum transferrin receptors are not available in clinical practice and the clinician has to depend on a 'full blood count' which estimates the common haematological indices $\mathrm{Hb}, \mathrm{Hct}$, $\mathrm{MCV}, \mathrm{MCHC}$ and $\mathrm{RBCC}$ in diagnosing iron deficiency.

The accuracy of detecing or excluding iron deficiency was low for all the readily available indices. As expected the RBCC was the least accurate $\left(43 \%\right.$ in $\mathrm{T}_{3}$ ). Although an $\mathrm{MCHC}$ of $<30 \%$ indicated that iron deficiency was present in all these cases (PPV 100\%), a MCHC of $<30 \%$ was found in only $38 \%$ of subjects who had iron deficiency (sensitivity $38 \%$ ). The MCHC had an accuracy of only $64 \%$ in $T_{2}$ and $71 \%$ in $T_{3}$.
A MCH of $<30 \mathrm{pg} / \mathrm{L}$ could detect $92 \%$ and $86 \%$ of subjects with iron deficiency in $\mathrm{T}_{2}$ and $\mathrm{T}_{3}$ respectively (sensitivity $92 \%$ in $\mathrm{T}_{2}$ and $86 \%$ in $\mathrm{T}_{3}$ ) and $80 \%$ of the subjects who had an $\mathrm{MCH}$ of $<30$ $\mathrm{pg} / \mathrm{L}$ probably did not have iron deficiency (NPV $80 \%$ ). However $76-79 \%$ of subjects who did not have iron deficiency were considered to have iron deficiency by this index (specificity 24-21\%). Although the accepted standard cut off points for Hct and MCV could correctly identify $96-98 \%$ of subjects who did not have iron deficiency (specificities 96-98\%) they failed to detect iron deficiency in $81-90 \%$ of those who actually had iron deficiency (sensitivites 10-19\%).

Although the accepted standard cut off points for $\mathrm{Hb}$ could identify $77-92 \%$ of those who did not have iron deficiency (specificity $77-92 \%$ ), 52-62\% of those who had iron deficiency were not detected (sensitivity $48-38 \%$ ). In a study done by us earlier we found that the $\mathrm{Hb}$ measured by the cyanmethhaemoglobin method had a sensitivity of $63 \%$ and a specificity of $58 \%$ in a group of subjects in whom the prevalence of iron deficiency anaemia was $69 \%$ (4). We have also shown that if 
a sample of blood from one subject was sent for estimation of $\mathrm{Hb}$ to three different laboratories the results could be significantly different from each other (16).

Results of haematological investigations should be interpreted with caution. Multiple indices should be evaluated. The best index to exclude iron deficiency in both $\mathrm{T}_{2}$ and $\mathrm{T}_{3}$ appears to be a $\mathrm{MCH}>30 \mathrm{pg} / \mathrm{L}$ (NPV $80 \%$ and $67 \%$ respectively). The best index to detect iron deficiency appears to be a MCHC $<30 \%$ (PPV $100 \%$ ) in $\mathrm{T}_{3}$ and the Hct in $\mathrm{T}_{2}$ (PPV 79\%). Therefore the combined use of these indices should improve the accuracy of the diagnosis of iron deficiency in pregnancy.

\section{Conclusions}

A single haematological index per se has a poor ability of detecting or excluding iron deficiency in pregnancy. The $\mathrm{MCH}$ had good sensitivity but poor specificity. The MCV and Hct have good specificity but poor sensitivity. Although the best index is the MCHC, its accuracy is only $64 \%$ in the second trimester. Therefore several indices should be evaluated before deciding on iron supplementation or therapy during pregnancy.

\section{References}

1. International Nutritional Anaemia Consultative Group. Iron deficiency in women. Washington. D.C. Nutrition Foundation, 1985; p 21-36.

2. Warren G.T. Comparison of tests for diagnosis of iron depletion in pregnancy. American Journal of Obstetrics \& Gynaecology 1988; 159: 1132-1134.

3. Puolakka J., Janne O., Pakarinen, Vihko R. Serum ferritin in the diagnosis of anaemia during pregnancy. Acta Obstetrica et Gynaecologica Scandinavia Supplement 1980; 95: 57-63.

4. Goonewardene M., Seekkuge J., Liyanage C. Iron Stores and its correlation to haemoglobin levels in pregnant women attending an antenatal clinic. Ceylon Medical Journal 1995; 40: 67-69.

5. Vanghan J.P, Morrow R.H. Manual of Epidemiology for District Health Management, WHO Publication Geneva 1989: p175178.

6. Earl R., Woteki C.E, Eds. Iron Deficiency anaemia: recommended guidelines for the prevention, detection, and managements among US Children and women of childbearing age. Washington DC. National Academy Press 1993.

7. Dacie J.V., Lewis S.M. Practical Haematology $8^{\text {th }}$ Ed. Edinburgh. Churchill Livingstone, 1994: $\mathrm{p} 669$.

8. Bunn H.F. Pathophysiology of the anaemias. In: Harrison's Priniciples of Internal Medicine Wilson JD, Fauci AS, Braunwald E, Isselbacher $\mathrm{KJ}$ et al Eds. $13^{\text {th }} \mathrm{Ed}$. Vol 2. New York: McGraw Hill Inc, 1997; p1717-1726.

9. Chard T., Lilford R.J. How useful is a test? J. Studd Ed. Progress in Obstetrics \& Gynaecology. 1986; 6: 3-15.

10. Armitage P., Berry G. Kappa measure of agreement. Statistical Methods in Medical Research, Oxford. Blackwell Scientific, 1994: p443-447.

11. Borel M.J.,Smith S.M., Derr Janice, Beard J.L. Day to day variation in iron status indices in healthy men and women. American Journal of Clinical Nutrition 1991; 54: 729-735.

12. Carriga M.T., Skikne B.S., Finley B., Cutler, Cook J.D. Serum transferrin receptors for the detection of iron deficiency in pregnancy. American Journal of Clinical Nutrition 1991; 54: 1077-1081.

13. Cook J.D., Skikne B.S., Baynes M.D. Serum transferrin receptors. Annual Reviews in Medicine 1993; 44: 63-74.

14. Goonewardene I.M.R., Fernando R.J., Liyanage C., Somasiri K.G. The agreement between haematological indices obtained by different methods. Galle Medical Journal 2000; 2: 13-17. 